\title{
Technology for producing nanomaterials taking into account anisotropic structure of raw materials
}

\author{
Aleksey Alekseevich Romanovich \\ Department of lift-and-carry and road machinery \\ Belgorod State Technological University named after \\ V.G. Shukhov \\ BSTU named after V.G. Shoukhov \\ Belgorod, Russia \\ 308012, Kostukov St., 46 \\ alexejrom@yandex.ru
}

\author{
Marina Alexeevna Romanovich \\ Department of lift-and-carry and road machinery \\ Belgorod State Technological University named after \\ V.G. Shukhov \\ BSTU named after V.G. Shoukhov \\ Belgorod, Russia \\ 308012, Kostukov St., 46 \\ alexejrom@yandex.ru
}

\begin{abstract}
The article gives detailed analysis of theoretical statements that exist nowadays and practice experience in the sphere of grinding materials to the nanosize. There is a technological scheme of the production of nanomaterials by the traditional method, which consists of two phases of grinding: pregrinding and deagglomeration of a pressed plate in the press-roll shredder and, finally, grinding in the rotor-vortex mill, operating in a closed cycle with a separator. The authors describe the construction of the press-roll shredder with a device for deagglomeration of the pressed plate of materials. This article presents the scheme and device operation. The authors also considered the issues of improving the efficiency by grinding materials with anisotropic texture. The main peculiarity of the specific features and conditions of organization of the process of grinding conditions, including the loading of materials with the anisotropic structure, the direction of their movement and the application of power load, was considered. The authors consider the conditions for the destruction of the anisotropic material between the eccentrically mounted rollers and an equation for the calculation of the specific force required to fracture anisotropic materials in the eccentric rolls PVI. The comparative data values of the specific quantities of grinding pressure during grinding organogenic limestone were revealed.

Keywords - technology for the production of nanomaterial with use of traditional assemblies: press-roll shredder and rotor-vortex mill, roller press mill with a device for feeding direction, anisotropic materials, grinding effort.
\end{abstract}

\section{INTRODUCTION}

It is well known that grinding the material to the nanosize is used to obtain new characteristics. For example, nanoceramic products with the grain size $(0.1 \mu \mathrm{m}=100 \mathrm{~nm})$ have their constructive and functional characteristics (wear resistant, strength, hardness, crack resistance, etc.) enhanced. This happens partly because the product made from nanoparticles has a more uniform distribution of density and sufficiently small gradients of internal stress when manufacturing the products by pressing.

The analysis of existing theoretical statements and practical experience in the domain of grinding materials to the nanosize remains quite power consuming for wide application in industry.
For example, it is known that for receiving the nanoparticle size of $10-15 \mathrm{~nm}$, it is necessary to use an electromagnetic method at the plant with productivity $\mathrm{Q}=40-200 \mathrm{~kg} / \mathrm{h}$. At that, the specific energy expenditure is $\mathrm{g}=50-60 \mathrm{~kW} \cdot \mathrm{h} / \mathrm{kg}$, which by several orders higher than power inputs of the device jet model, the vibratory mill and etc. $(\mathrm{g}=0.1-0.25 \mathrm{~kW} \cdot \mathrm{h} / \mathrm{kg})$. they provide the production of the fine-grained product with the particle size of 1-10 $\mu \mathrm{m}$ or less [1-3].

Even the large dispersion in the size of the nanoparticles and the micro-level is not a convincing argument for the huge energy expenditure in the production of nanomaterials and their possible use in the wide branches of industry. Furthermore, sufficiently low productivity in the production of nanomaterials hinders their wide using in the industry.

In the authors' opinion, all this demonstrates the need for complex approach in solving difficult problems of nanotechnology, all the more so, if it is necessary to grind initial raw materials to a significant size $(50-30 \mathrm{~mm})$.

The analysis of technical and economic efficiency of using existing grinding systems in industry for production finely dispersed materials allowed one to classify them in the following order: the tube mill in the closed cycle with the centrifugal separator (TM - CS); the roller mill with the integrated separator (RMS); jet mill with the straight-through separator and before grinding in the rod (rattler) mill (RM$\mathrm{JM})$; the tube mill with the closed cycle before grinding in the press-roll shredder (PRS -TM) [2].

These systems cover the basic technical solution in the sphere of grinding with records of existing grinding assemblies and the prospects of its development.

Table I shows comparative characteristics of the mentioned grinding systems with a regulated content of the fine fraction (55 - 60\% fraction 5-30 $\mu \mathrm{m})$ [4-6].

These data demonstrate expediency of using materials for grinding by the method "crushing with shift", implemented in VMS and PVI. Besides that, the result of the research shows that there are commensurable specific power inputs during grinding of the clinker to $S=300 \mathrm{~m}^{2} / \mathrm{kg}$ up for the method of 
crushing with shifts - 2.5- $5.8 \mathrm{~kW} \cdot \mathrm{h} / \mathrm{t}$, for free kick $25-58$ $\mathrm{kW} \cdot \mathrm{h} / \mathrm{t}$; for the combination of kick-crushing and abrasion $32 \mathrm{~kW} \cdot \mathrm{h} / \mathrm{t}$

The efficiency of grinding for the roller assembly (crushing) is (50-70) $\cdot 10^{-4} \mathrm{~m}^{2} / \mathrm{J}$, for the ball rattler (composite action)-(10-40) $\cdot 10^{-4} \mathrm{~m}^{2} / \mathrm{J}$.

Without denying the expediency of development VMC in the industry, in the authors' opinion, the greatest effects and faster returns with minimal cost can be obtained during a wide using of system PRS-TM. This is evidenced by the experience of exploitation of mills, equipped with PRS abroad, spreading rapidly since 1985 .

TABLE I. COMPARATIVE CHARACTERISTICS

\begin{tabular}{|c|c|c|c|c|c|c|}
\hline \multirow{3}{*}{ Indicator } & \multicolumn{6}{|c|}{ Grinding systems } \\
\hline & \multirow{2}{*}{$T M-C S$} & \multirow{2}{*}{$R M S$} & \multicolumn{2}{|c|}{$R M-J M$} & \multicolumn{2}{|c|}{ PRS-TM-CS } \\
\hline & & & $R M$ & $J M$ & $P R S$ & TM-CS \\
\hline $\begin{array}{l}\text { Characteristics of } \\
\text { the shredder: }\end{array}$ & & & & & & \\
\hline size, $\mathrm{m}$ & $4.2 \times 14$ & 2.9 & $3.2 \times 4.5$ & - & $1.0 \times 0.8$ & $1.8 \times 1.4$ \\
\hline weight, t. & 800 & 350 & 300 & 150 & 60 & 590 \\
\hline $\begin{array}{l}\text { Installed power of } \\
\text { the electric }\end{array}$ & 3500 & 2900 & 900 & 7600 & 500 & 3250 \\
\hline $\begin{array}{l}\text { motor, kW. } \\
\text { Power } \\
\text { consumption of } \\
\text { the drive, } \mathrm{kW} \text {. }\end{array}$ & 3220 & 2470 & 810 & 6800 & 4060 & 2320 \\
\hline $\begin{array}{l}\text { Specific energy } \\
\text { expenditure by } \\
\text { grinding clinker } \\
\mathrm{kW} \mathrm{h} / \mathrm{t} \text {. }\end{array}$ & 32.2 & 24.7 & 81 & 68 & 4.6 & 32.2 \\
\hline
\end{tabular}

It is known that using PRS provides the reduction of specific energy expenditures by $25-40 \%$ and the increase in productivity of the grinding assembly by $15-40 \%$. For example, specific energy expenditures, covering the pregrinding of clinker in PVI with a diameter of rolls of $1 \mathrm{~m}$ is 3 $4 \mathrm{~kW} \cdot \mathrm{h} / \mathrm{t}$, which fits $\mathrm{q}_{\mathrm{vms}}=7-10 \mathrm{~kW} \cdot \mathrm{h} / \mathrm{t}$, covering similar refinement of grinding in the rotary mill [7-11].

However, despite the clear superiority in energy expenditures and high unit power, traditional grinding systems, carried out using the ball rattler, have the specific shortcoming. It construction is a rather problematic for producing a material with a particle size $(5-10 \mu \mathrm{m})$, not to mention nanoparticle.

The authors have proposed the technology for the production of superfine materials (fig. 1), consisting of the press-roll shredder for preliminary grinding of materials and the rotary-jet mill (RVM), which is used in the capacity of the grinding assembly. It allows one to receive the end product with a high specific surface available in size over the range of 500 - 100 NM.

The process of grinding materials in PRS is poorly studied, and data on the grinding of brittle materials in PRS [12-14], reported in the literature, indicate to a large variation from 0.5 to $1.5 \mathrm{~m} / \mathrm{c}$ of rotation speed of the rolls, grinding efforts $\mathrm{P}=150$ - $350 \mathrm{MPa}$, overall size of the rolls (diameter is $1.0-2.8 \mathrm{~m}$; breed is $0.8-1.6 \mathrm{~m}$ ) and exit metrics (specific energy expenditure is $1.5-5.0 \mathrm{~kW} \cdot \mathrm{h} / \mathrm{t}$ ). The installed power of engine can reach up to 4.5 thousand $\mathrm{kW}$, and productivity of plants range from 10 to $1800 \mathrm{t} / \mathrm{h}$ ). All this indicates the necessity of theoretical and experimental research on the process of grinding materials in PRS to receive an efficient constructivetechnical and power-operated parameter of the assembly, with records of the physical and mechanical characteristics and the texture of grinding materials.

When implementing the stepwise grinding of materials, materials are preprocessed under pressure between rollers PRS, after which the materials come out in the form of pressed plates with maximum strength in the line for application of force and have an anisotropic structure (Fig. 2).
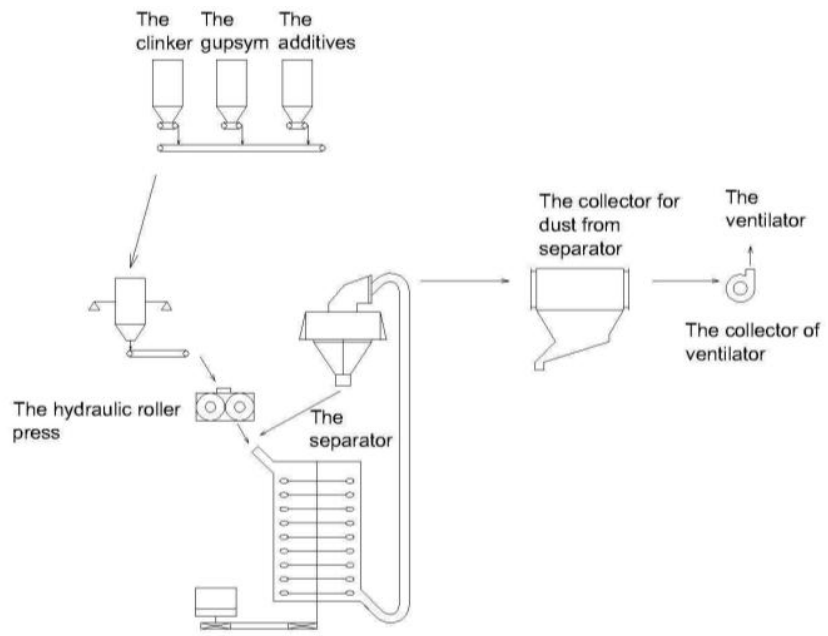

Fig. 1. The techological scheme for the produce of mineral powder

This form of particles makes its deagglomeration and grinding in such assembly difficult because of vibration, jet, rotor-vortex mills, etc., which allows producing a new product with a high specific surface area.

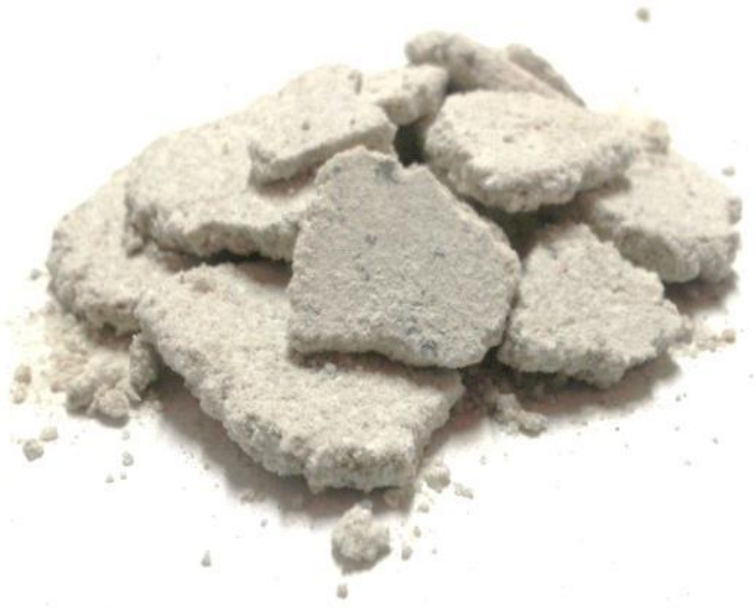

Fig. 2. The form of slag after processing by pressure in PRS

The experimental research on the effect of pressure grinding materials in PVI by the value of force of deagglomeration of pressed plates (fig. 3) revealed that with 
increasing compaction pressure, not only the fineness of the material increases, but also the strength of the pressed plates does. Herewith, for its deagglomeration it is necessary (depending on the direction) to apply various values of force. During the grinding of the slag by the pressure of $240 \mathrm{MPa}$, which corresponds to the saturation of both the degree of fineness and the density of the compacted plate, the force needed for deagglomeration of the material in the direction of pressing is $\mathrm{R}_{\text {dea.leng }}=22 \mathrm{MPa}$, which is 5 times higher than the force of destruction in the perpendicular direction, equal to $\mathrm{R}$ dea. cross $=4 \mathrm{MPa}$. This shows that for deagglomeration of material crushed and compressed into a plate in PRS, it is advisable to apply the force of its destruction in the direction perpendicular to compression or combination of crushing and shearing deformation.

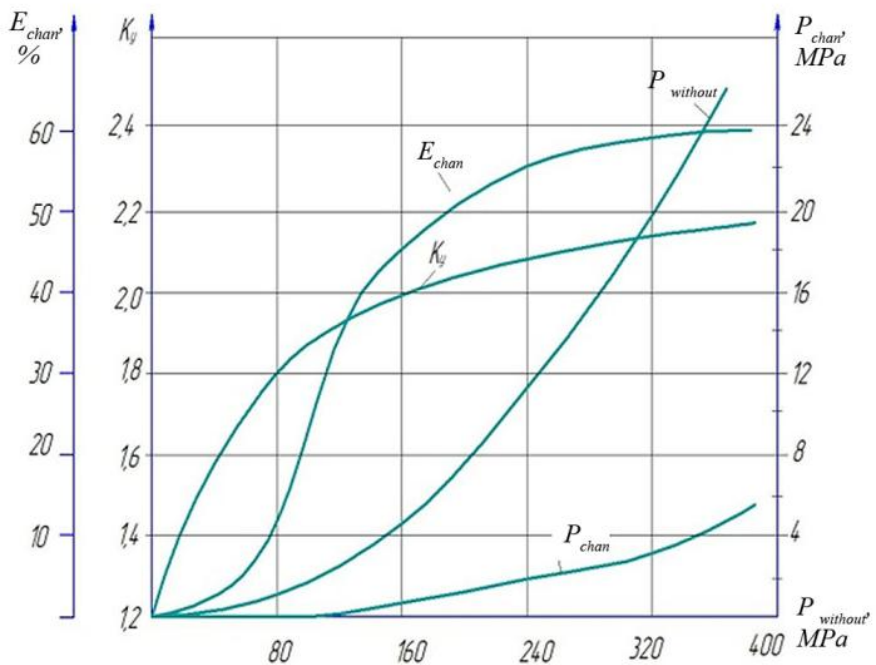

Fig. 3. Effect of pressure of grinding slag on size of strength of deagglomeration of pressed plates

The authors have developed a PRS design with a device for deagglomeration of the compressed tape that allows one to combine the process of grinding with disaggregation of pressed materials, thereby decreasing operating costs and improving the effectively of using the grinding assembly (fig. $4)$.

The press-roller shredder with a device for deagglomeration consists of loading tray 3, conical rollers 1 that are installed on the framework and a deagglomeration device. This device consists of additional rollers 2 that revolve towards each other. The additional rollers have fewer diameters, and the taper is the reverse of fundamental conical rollers, which allows realizing power effect onto pressed plates in the line of their minor strength.

The authors developed a design of the press-roller shredder that is installed in the processing line for the production of mineral addition and has the following performance attributes presented in Table II.
TABLE II. PERFORMANCE ATTRIBUTES OF PRESS-ROLLER SHREDDER

\begin{tabular}{|l|c|}
\hline \multicolumn{1}{|c|}{ Indicator } & Size of index \\
\hline Total dimensions of rollers D $\times \mathrm{B}, \mathrm{m}$ & $0.4 \times 0.25$ \\
\hline Size of taper of rollers & $0.05-0.35$ \\
\hline Rotational speed of rollers, $\mathrm{s}^{-1}$ & $0.15-1.0$ \\
\hline Maximum efforts of grinding, N & $5.0 \times 10^{6}$ \\
\hline Power of drive, Wt. & $18 \times 10^{3}$ \\
\hline
\end{tabular}

The assembly for grinding and deagglomeration of materials works in the following way. In loading tray 1 starting material is supplied, which is grabbed by rollers and between which its destruction is realized. Coming out of the space of PRS between rollers, the materials obtain the form of pressed plates, the destruction of which is realized between additional rollers due to application of efforts in the line of the reverse pressing that allowed one to produce not only its deagglomeration, but also uncover micro fissure of plates.

$\mathrm{a}$

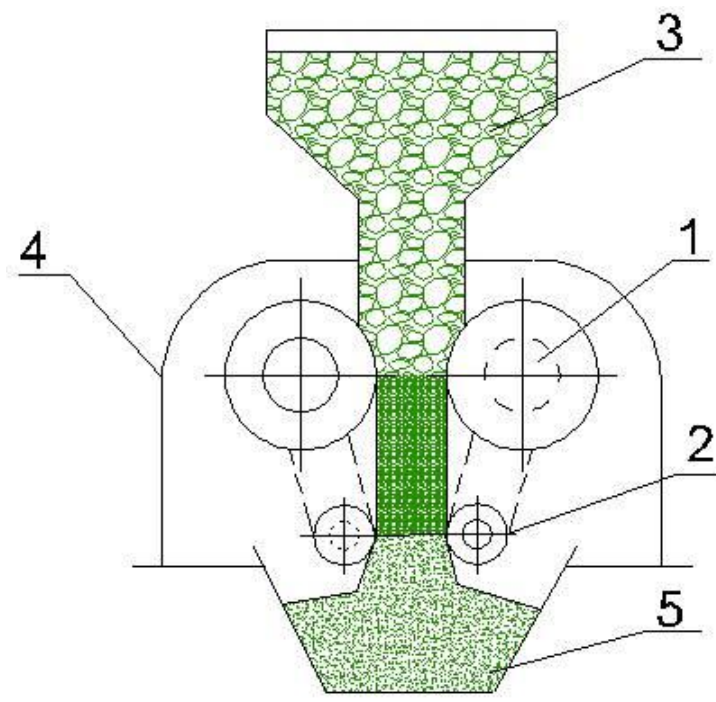

b

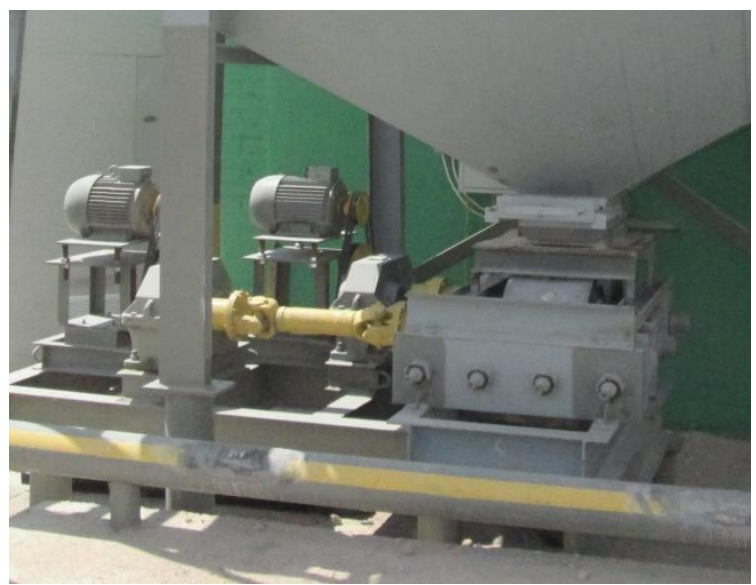

Fig. 4. PRS with device for deagglomeration of pressed materials: a constructional scheme of plant: 1 - fundamental conical rollers; 2 additional rollers; 3 - bunker; 4 - PRS; 5 - bunker; b - photo of experimental industrial assembly 
As the research showed, depending on the crushed materials and conditions of their grinding, pressure in PRS, with allowance of the end product of about $30 \%$, the size of granules is less than $80 \times 10^{-3} \mathrm{~mm}$. The moving off of the end product after assembly of final grinds not only greatly decreases specific costs, but also raises effectively its works. The next grinding of slag is realized in the shock vortex mill, working in the closed loop with the separator (fig. 5, 6). The experimental industrial plant of the rotor-vortex mill has the following characteristics: total dimensions of assembly are 0.6 $\times 1.5, \mathrm{~m}$; the rotational speed of rotor is $30 \mathrm{~s}^{-1}$; adjusting drive power is 100 watts; productivity is 10 tons / hour.

Pre-grinded in PRS, the material enters the RVM, where it comes under the influence of the rotating rotor with a frequency of $1800-2000$ min-1. The material is grinded when it enters the beating rotor, then it is picked up by the air flow generated by the rotor and is sent via the line to a separator where it is separated into fractions.

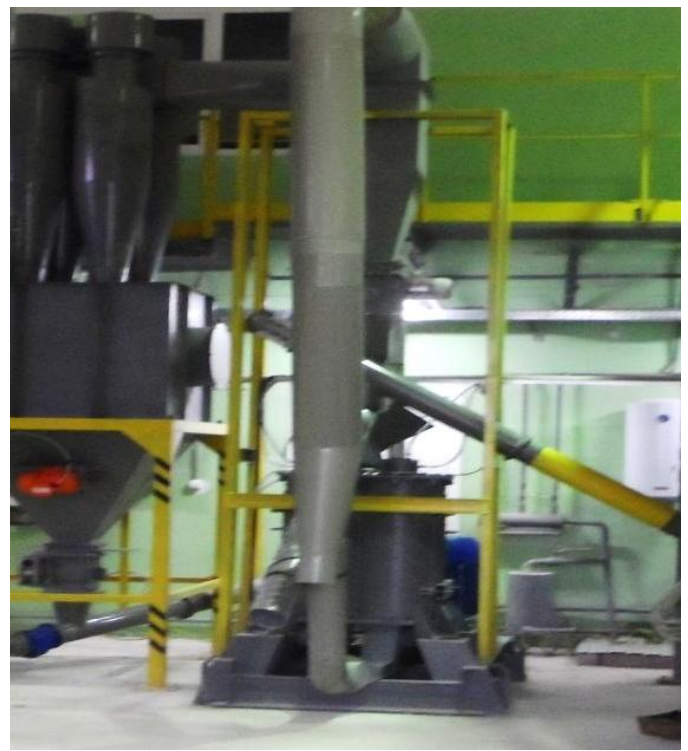

Fig. 5. Photo of experimental industrial rotor-vortex mill

While the material is rotating in the air flow and moving into the mill shell and magisterial, it is reground. After the separation, the finished product is stored in a hopper and nonreground material is directed to the regrinding of the rotorvortex mill. To avoid aggregation of the fine product in the rotor-vortex mill, plasticizers are introduced into grinding.

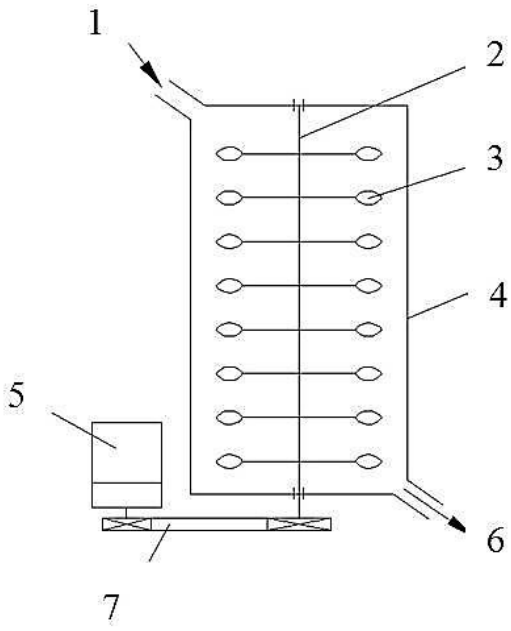

Fig. 6. Construction scheme of rotor-vortex mill: 1 - entering jet, 2 - rotor, 3 - beater, 4 - frame, 5 - electric motor, 6 - unloading jet; 7 - vee - belt drive

In the last decade, there is a quite urgent question about recycling of industrial wastes, which are formed during the extraction of metallic and non-metallic minerals. The tailings stored annually amount to about tens of billions of tons of rocks, which, by their mineralogical composition may well be used in the manufacture of a wide range of building materials. Produced rocks differ from the traditional raw material construction industry by its geological origin, mineralogical composition, structure and physic-mechanical properties. A special place among these belongs to anisotropic materials having different physical and mechanical parameters of the medium (compressive strength, tensile, bending, Young's modulus, shear, Poisson's ratio, dielectric, magnetic permeability, and others, Table III)

Numerous studies of scholars confirm the direct dependence of anisotropy $\mathrm{K}_{\mathrm{AN}}$ :

$$
K_{A N}=\frac{\sigma_{\perp}}{\sigma_{\|}}
$$

where $\sigma_{\perp}, \sigma_{\|}$. Accordingly, the tensile strength of the anisotropic material is in directions perpendicular and parallel to the layering of minerals

These circumstances attract much attention of academics and practitioners in the development of processing technologies and constructive improvement of crushing and milling equipment to save energy during grinding materials with the anisotropic texture [5].

In this regard, there is a special relevance in the uniform direction and power units used for the destruction of materials, having an anisotropic structure, since it becomes possible to provide directed force action on the material to be ground in the direction of its smallest strength, thus significantly reducing the energy consumption for grinding.

When splitting anisotropic rocks, the destruction efficiency of the process depends on many factors: the strength characteristics of materials, their structural and textural 
features, the main way and the direction of the application of destructive forces. Analysis of the scientific and technological research of the process of fracture of isotropic and anisotropic materials in various crushing and grinding units shows that the organization of the grinding process of anisotropic materials should take into account not only their specific characteristics, but also the conditions of organization of the process:

- Loading conditions of materials with the anisotropic structure and direction of their movement.

- Direction of application of power load.

- Technological schemes of processes of grinding material at each stage of processing (classification of ground products, internal and external recycled crushed materials, separation finely divided entity, etc.).

TABLE III. PROPERTIES OF ANISOTROPIC MATERIALS

\begin{tabular}{|c|c|c|c|}
\hline \multirow{2}{*}{$\begin{array}{c}\text { Identification of } \\
\text { substance }\end{array}$} & \multicolumn{2}{|c|}{ Compressive strength, MPa } & \multirow{2}{*}{$\begin{array}{l}\text { Anisotrop. } \\
\text { factor }\end{array}$} \\
\hline & $\begin{array}{l}\text { Perpendicular } \\
\text { to foliation }\end{array}$ & $\begin{array}{c}\text { Parallel to } \\
\text { foliation }\end{array}$ & \\
\hline $\begin{array}{c}\text { Organogenic } \\
\text { limestone's }\end{array}$ & 95 & 65 & 1.46 \\
\hline Schist's (mine KMA) & 130 & 59 & 2.2 \\
\hline $\begin{array}{c}\text { Amphibolite (Mine } \\
\text { KMA) }\end{array}$ & 145 & 75 & 1.93 \\
\hline $\begin{array}{c}\text { Quartzite-sandstone } \\
\text { banded }\end{array}$ & 260 & 190 & 1.37 \\
\hline
\end{tabular}

Existing fleet of crushing equipment for today, both in Russia and abroad, do not take into account features of the crushed materials.

The analysis of the conditions of the expiration of the charge and its crushing compression in the press roller assemblies demonstrates the feasibility of using the feed roller-type devices that provide uniform distribution of the mixture layer throughout the width of the working bodies of PVI, its effective preconsolidation I feed direction of the material layer in the roll space. The authors have to level the design of the invention of the press roll grinder with a device for supplying directional anisotropic materials (fig. 7).

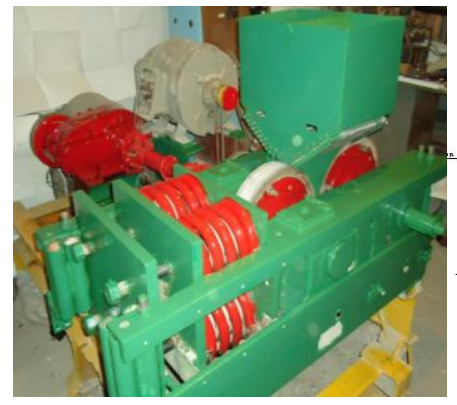

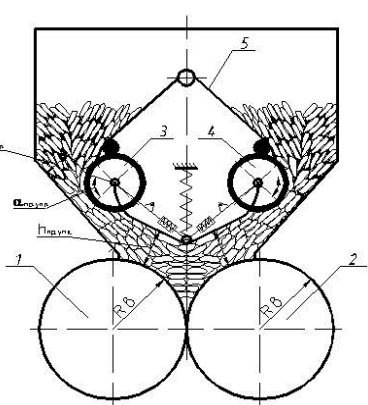

Fig. 7. Roller press mill with device for feeding direction of anisotropic materials: $\mathrm{a}$ - photo of experimental setup, $\mathrm{b}$ - scheme of work

The press roller crusher consists of an eccentric roller mounted on frame 1,2 , on which inside there is the hopper of a roller unit consisting of two movable cheeks 5 in contact with the shaft and rollers 3, 4 interconnected by movable guide rods. The unit operates as follows. A material having the anisotropic texture, for example, organogenic limestone and others, is fed into the hopper, where movable cheeks 5 are fed to rollers 3 and 4 and are gripped by them, rotated in the longitudinal position, and sealed, uniformly distributed over the width of the roll and guided in the roll space.

Then the material is captured by eccentric rollers 1,2 , where crush-shear deformation is implemented due to the different peripheral speeds of the working surfaces of the rolls. The gap between spring rolls 3, 4 is set within value $H=R_{a v}(1-\cos \alpha)+\delta$ (wherein $\alpha$ - angle of rolls, $R_{a v}$ average radius of current roll, $\delta$-gap between the eccentric rollers).

The experimental results confirmed the efficiency of this design and PVI and high efficiency of the use of the grinding materials with the anisotropic texture.

However, the complexity of the implementation of these aggregates in real production is largely predetermined by the lack of methodology calculating the amount of effort required in the fracture and anisotropic materials.

Implementation of effective modalities of crush-directional shear force action on the anisotropic material can press roll grinders with eccentrically mounted rollers. Let us consider conditions of fracture anisotropic material between the eccentrically mounted rollers (fig. 8) assuming that the normal stresses in anisotropic material, uniformly distributed on the arc of the rolls in the deformation zone, and the greatest efforts the grinding are achieved by the line connecting the centers of the rolls.

$\alpha)$
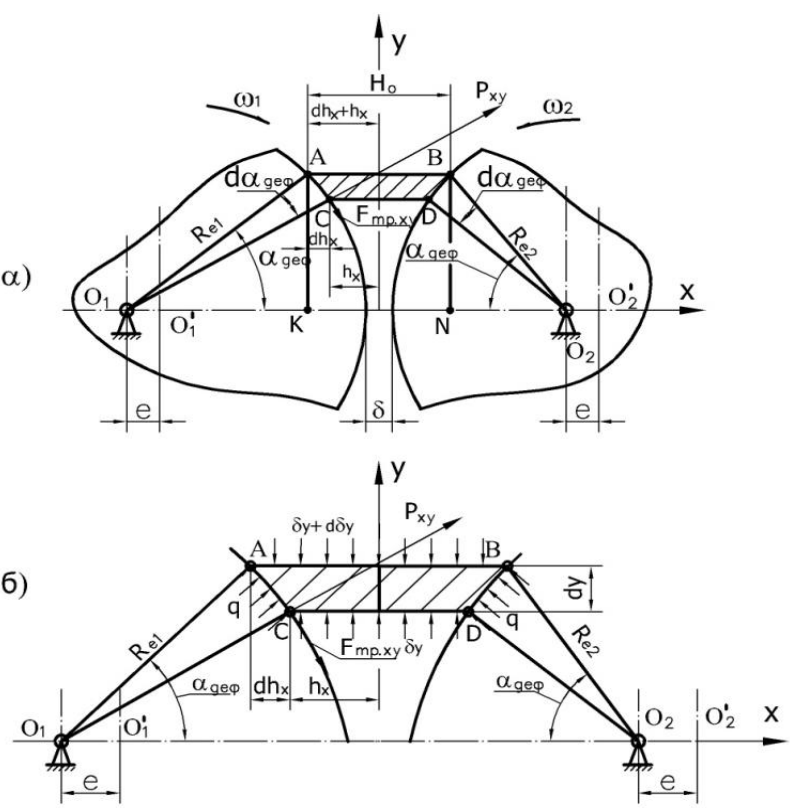

Fig. 8. Driving forces to determine grinding force

After appropriate transformations, let us obtain the equation for the calculation of the specific force required to fracture anisotropic materials in eccentric rolls PVI. 


$$
\begin{gathered}
\left.P_{i}=\frac{0,71 f L \alpha_{\kappa} \sigma_{s g}}{k_{a n}}\left(\operatorname{tg} \gamma-f_{T}\right) / e^{\frac{5 L \mathcal{L} \delta}{S \cos \alpha}}\right) \cdot \frac{H_{0} \cdot \operatorname{tg} \alpha_{d e f}}{\Delta h f_{T}\left(f_{T}+\operatorname{tg} \alpha_{d e f}\right)} \cdot \\
{\left[1+\frac{f_{T}}{\operatorname{tg} \alpha_{\text {def }}}\left(1-\frac{2\left(H_{0}-\delta\right)}{H_{o}}\right)-\frac{\left(\operatorname{tg} \alpha_{d e f}-f_{T}\right)}{\operatorname{tg} \alpha_{d e f}}\left(\frac{H_{o}}{h_{x}}\right)^{f_{T} / t g \alpha d e f}\right]}
\end{gathered}
$$

where, $G_{s g}$ - tensile strength of anisotropic materials under compression, $\mathrm{N} / \mathrm{m}^{2} ; \operatorname{tg} \alpha_{d e f}$ - angle deformation of the charge layer; $\mathrm{f}, f_{T}$ - accordingly, coefficients of internal and external friction; $S$ - area of the crushing chamber, $\mathrm{m}^{2} ; L$ - perimeter of the crushing chamber, $\mathrm{m} ; \alpha_{\mathrm{\kappa}}-$ angle of application of power load, hail; $\xi$ - coefficient of lateral thrust; $\operatorname{tg} \gamma$ average value of the angle of inclination of the contact area of anisotropic particles, the three mutually perpendicular axes; $\mathrm{H}_{\mathrm{o}}$ - the thickness of the particle layer in the beginning of deformation, m; $\Delta h$ - deformation of a layer charge at its destruction, m; $K_{A N}$ - coefficient of anisotropy of the material; $\alpha$ - angle of maximum effort; $\delta$ - value of the roll gap, m.

The plot (fig. 9), constructed according to equation (2), has shown that increasing the radius of the roll leads to an increase of grinding effort. This indicates that the increase in the radius of the rolls leads to increased thickness of the material and the gripping rollers area zone of maximum effort, and consequently $\mathrm{L}$ and $\mathrm{S}$, which requires great effort of grinding.

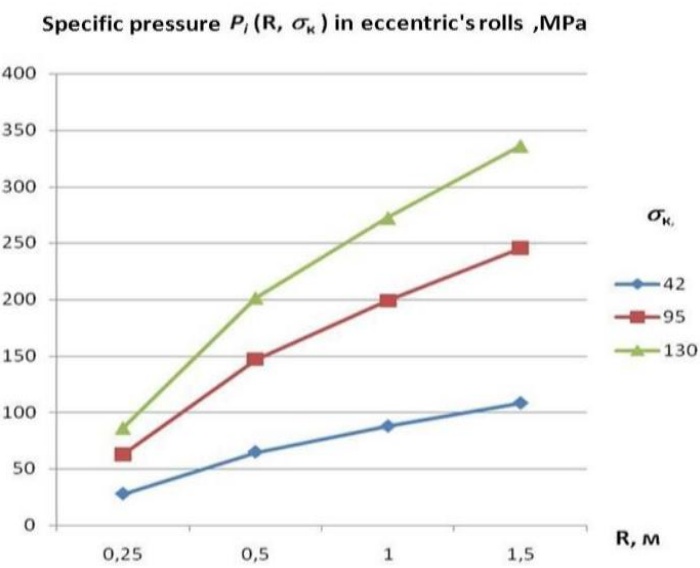

Fig. 9. The effect of the radius of the roller on the specific pressure failure in IMC anisotropic materials with different compressive strength

Grinding effort also increases with the initial strength of crushed material that allows one to make important practical conclusion that the grinding anisotropic materials are necessary to create the force effect in the direction of the least resistance. This requires the development of the device that would direct their feed to the rolls of PVI.

\section{CONCLUSION}

Let us summarize the following results:
1) The obtained equation allows determining the value of the current crushing resistance-shear deformation of the charge layer on the basis of the geometrical parameters of the press roller crusher with eccentric rollers and physicmechanical properties of crushed anisotropic material. Comparing the values of specific variables, the grinding pressure during grinding limestone organogenic is $\left(G_{s g}\right.$ $=95 \mathrm{~N} / \mathrm{m}^{2}$ ). Preparations of experimental PVI, with $\mathrm{R}=0$ to 5 $\mathrm{m}$ and equal to $141 \mathrm{MPa}$ by calculation amounting to 148.6 $\mathrm{MPa}$, determined that the difference does not exceed $10 \%$. Thus, the resulting expression (3) is adequately reflects the actual process

2) For the wide dissemination of nanomaterials in industry along with inefficient methods used (electromagnetic, chemical, etc.), it is necessary to improve a high-productive traditional grinding system. Developed technology of grinding material includes two phases: pre-phase - in a roller press unit, and a final phase - grinding in a rotor-vortex mill operated in closed cycle with the separator allowing one to obtain a finished product with a high specific surface and particle sizes of $500-300 \mathrm{Nm}$. Using a feedstock material with these particle sizes in many industries provides a significant effect on improving the properties of the final products.

\section{Acknowledgment}

The work is realized in the framework of the Program of flagship university development on the basis of Belgorod State Technological University named after V.G. Shoukhov, using equipment of the High Technology Center at BSTU named after V.G. Shoukhov.

\section{References}

[1] V.V. Sevostyanov, I.I. Targonskii, A.A.Romanovich, and A.A Goncharo, "Energy saving milling aggregates with internal recycling of the milled materials," Glass and Ceramics, 50 (4), pp. 180-184, 1993.

[2] A.A. Romanovich, "Energy saving in production of building products," Bulletin Belgorod State Technological University named after V.G. Shukhov, 3, pp. 69-73, 2011.

[3] A.A. Romanovich, "The distinctive features of stepwise grinding of materials using a press-rolling grinding mill," News of higher educational institutions. Construction, 9, pp. 88-91, 2014.

[4] M.R. Jones, "Estimation of the filter content required to minimize voids ratio in concrete," Cement and Concrete Research, 2003.

[5] V.S. Bogdanov, A.A. Romanovich, N.D. Vorobyov, "Definition of rational conditions of materials grinding in energy-saving milling complex," World Applied Sciences Journal, vol. 25(2), pp. 214-221, 2013 .

[6] A.A. Romanovich, "Energy saving in the manufacture of building products," Bulletin of BSTU named after V.G. Shukhov, vol.3, pp. 6971, 2011.

[7] L.G. Romanovich, M.A. Romanovich, V.V. Vybornova, V.N. Riapukhina, "Small business is a sphere of innovation in the age of globalization," Journal of Applied Engineering Science, 12 (4), pp. 297 301, 2014.

[8] "The world's largest roller mills," International cement review, 1, pp. 43 44, 2000.

[9] V.S. Bogdanov, I.A. Semikopenko, P.P. Penzev and A.N. Maslovskaya, "Desintegrator with unit high-speed flow of crushed material," Bulletin of BSTU named after V.G. Shukhov, 1, 2009, pp. 101-103.

[10] V.K. Pobeda, "Press roller grinders JSC "Tyazhmash"," Cement and its application, 4, pp. 26-28, 2007. 
[11] M. Metsman, Y. Krump, "Technology to upgrade the cement plants of the company KHD Humboldt Wedag GmbH," Cement and its application, 3, pp. 40-43, 2005.

[12] H. Wustner, "Energy - saving with the roller press comminution process," World Cement, 3, pp.94-96, 1986.

[13] A.A. Romanovich, "Performance review and principal directions for development of grinding equipment in cement factory," Journal of Engineering and Applied Sciences, 9(11), pp. 2367-2370, 2014
[14] A.A. Romanovich, A.M. Gridchin, V.S. Lesovik, "Geological and lithological bases of calculation and design of equipment for crushing rock," Belgorod: BSTU after V.G. Shukhov, 2012, 350 p.

[15] M. Young, "The Technical Writer's Handbook. Mill Valley," CA: University Science, 1989. 